\title{
Strategic opportunities: Leveraging decision-making indicators
}

\author{
Gordon Bowen \\ Northumbria University London Campus \\ ghgb@hotmail.com
}

Deidre Bowen

Epic Partners, UK

Richard Bowen

Walmart eCommerce, USA

\begin{abstract}
Politicians tend to use the word opportunity as a catch-all term. This paper is contending that opportunities can be classified as tangible or intangible. Lawmakers do not appear to consider the idea that opportunities are hierarchical or link to a firms' ability to leverage opportunities. The context for the paper is Brexit and its strategic implications. Furthermore, a hard Brexit will throw up more intangible opportunities than tangible opportunities, which suggests that firms will require different strategies for hard Brexit and soft Brexit environments. This paper suggests that there are two possible dominant strategies available to executives, namely leverage logic and opportunity logic, and the application of the strategies is dependent on the type of Brexit situation. The time horizon to develop and refine the dominant strategies is dependent on the type of Brexit environment, with a hard Brexit requiring the longest time horizon.
\end{abstract}

Keywords: Opportunities, strategy, decision-making, environmental scanning, industry entry, Brexit

\section{Key terms and definitions}

Brexit - the leaving of a country from a trade block union to form bi-lateral agreements

Competitive advantage - ability to outperform competitors and create additional value

Environmental changes - changes that occur in the business environment beyond the control of the organisation

Opportunity - leverage strategies that the organisation can use to exploit trends and opportunities in the business environment 
Political uncertainty - impact of government decision making, which causes many unknowns to be generated

Referendum - vote given to the people in a country to decide on a political policy or action

Resources and competences - assets that can be exploited to bring efficiency to the organisation, and competences are the ability to apply techniques and skills in different situations

Strategic planning - formulating a process to analyze the business environment that is beneficial to the organisation

Strategy - future direction of the organisation and where the organisation wants to be

The 2016 Referendum called by the Conservative United Kingdom (UK) government was to decide whether to stay in the European Union (EU) or leave. Thus the referendum was a binary choice: leave or remain. Different political narratives have evolved to give context to the different sides of the political event. The outcome of this important event was a victory for the leave-side of the campaign. According to the 'Leavers' the victory meant the UK should exit the EU as a clean break, i.e. with or without a deal. The idea of a political exit without a deal gave rise to the name 'hard Brexit'. Leaving with a deal is designated a 'soft Brexit'. One of the many differences in political ideology between the two camps is the idea of taking back control from the EU. The 'Remainers' suggested control could be modified by working within the EU. Associated with leaving the EU in the eye of the Leavers is the ability to set trade deals and be free from the EU laws. This paper will focus on the idea that freedom from the EU will allow the UK to secure trade deal opportunities beyond the EU, and that these would be numerous and advantageous. This narrative gives rise to the mindset that the freedom to strike trade deals, independent of the EU, would bring more trade opportunities to the country. At the time of writing this paper the UK has secured seven continuity trade deals from a target of 40, with the Pacific Islands, Israel, the Palestinian Authority, Switzerland, The Faroe Islands, Eastern and Southern Africa and Chile.

The state of the Brexit debate is that the UK will leave the EU. Leaving the EU is under the terms of the EU Withdrawal Agreement. The agreement has been put to the UK Parliament twice and has been rejected (by enormous margins) on both occasions. An attempt by the government to bring the EU Withdrawal Agreement to the UK Parliament again for a third time was ruled inadmissible by the Speaker of the House. However, if there is a major change to the EU Withdrawal Agreement the Speaker of the House will allow a third vote. The Speaker of the House determines if the EU Withdrawal Agreement has undergone significant changes so as to be deemed a new bill. There are plans to bring the bill to the UK Parliament again just before the UK is due to leave the EU on 29 March 2019. Unfortunately, the UK Parliament cannot agree on an alternative to the government's EU Withdrawal Agreement. Consequently, the government has applied to the EU for a short extension to Article 50, until June 2019. This is still under consideration by the EU, but the expectation is that it will be granted. Where does this leave Brexit? Several options have been mentioned. These options include to leave the EU based on the terms of the EU Withdrawal Agreement or that 
the UK Parliament wrest control of the Brexit process from the government and vote on a number of indicative scenarios e.g. second referendum, Norway style agreement with the EU. There is no appetite for leaving the EU with a no deal, but this could become a default outcome due to the complexity of the process. There is also a possibility that the UK remains in the EU (preferred option by the EU). The outcome of Brexit is inconclusive: the three actors - UK Parliament, UK government and the EU need to reach a consensus.

The word "opportunity" when used colloquially gives the impression that there is no need to qualify an opportunity. This is certainly how politicians use the word, which is different from how businesses would use it. In the business world opportunities must be qualified, because not all opportunities are exploitable, but how opportunity is used by politicians, especially in relation to Brexit, gives the impression that all opportunities are exploitable or are equal. The use of the word opportunity is exaggerated, and gives people a false impression of beneficial choices. Opportunity can be "tangible" or "intangible", and these two options are at the opposite end of the opportunity continuum. Tangible opportunities are exploitable, and have a good degree of success, whilst intangible opportunities are likely to be unsuccessful, because the ability to exploit them is lacking in some way. Both tangible and intangible opportunities are strategic in nature, but tangible opportunities are more likely to be successful based on a firm's capability. The risk associated with exploiting tangible opportunities is much lower than that of intangible opportunities. Leavers argue that freedom to make trade deals independent of the EU will lead to more opportunities, i.e. tangible opportunities.

Tangible opportunities will enable firms to apply their existing competencies in a soft Brexit environment, with minimal recombination. The level of adaptability required for a hard Brexit environment will require a substantial rethink on how a firm can remain competitive. The agricultural industry could be devastated, because the industry receives significant subsidies from the EU and the UK government will find it challenging to match the subsidies the industry currently enjoys. If a hard Brexit is the outcome, the government is suggesting tariffs could be zero for many agricultural imports, which would impact the industry severely. The agricultural industry would enjoy more tangible opportunities in a soft Brexit world, because the ruggedness of the business environment would be based on an incremental change, and not a transformational change that would exist in the hard Brexit environment. Tangible opportunities will still exist in the hard Brexit environment, but the recombination of the competencies will require an elongated window of opportunity, i.e. it will take longer for competitors to find a suitable strategic position in a hard Brexit environment. This will necessitate different strategies such as partnerships or collaborations with firms inside and outside the UK. Some universities have formed relationships with EU universities to maintain access to EU funding for research and signal to EU students that they can continue to study in the UK. Kings College, Warwick University and LSE are some of the first to adopt a first mover strategy with partnerships with EU universities. The financial services industry has adopted a similar strategy to the universities. It entails the banks moving parts of their business to EU countries to enable continued business interaction with the EU. These are precautions to offset the impact of a hard Brexit, because of the uncertainty surrounding the Brexit event. Even the government has reached side-deals with the EU for pharmaceutical products from the UK to be compliant with EU law. Conclusively, a hard Brexit will include more intangible opportunities and to exploit 
them successfully will require firms to consider different methods of strategies. These would range from joint ventures, partnerships, collaboration to creating subsidiaries in the EU.

Without analysis of forecast environmental trends the scope to define effective opportunities is limited. There is a tendency to treat opportunities as strategies, and link them to the firm or consider them as strengths, without scanning the environment (Siciliano, 2016). Favorable environmental trends give rise to "tangible opportunities". The indicators to exploit favorable environmental trends form a focus of this paper. The literature uses the resource-based view (RBV), and Blue Ocean and strategic positioning are frameworks that aid understanding of the factors that contribute to tangible opportunities (Kim \& Mauborgne, 2005; Peteraf, 1993; Barney, 1991; Porter, 1996). However, uncertainty in the environment could influence the effectiveness of the application of these frameworks, and thus question the importance of the indicators used to define the quality of the opportunity or whether to classify the opportunity as a tangible opportunity. A clean break from Europe is the requirement of a hard Brexit and entails leaving the European Union (EU) and single market. This will enable the UK to trade on World Trade Organization (WTO) regulations. However, a soft Brexit envisages the UK retaining some form of membership of the EU and that includes the single market and/or customs union. The various models will have an impact on economic growth, but soft Brexit will cause the least dislocation (BBC, 2016). Hard Brexit is non-alignment with EU trade regulations and processes, whereas soft Brexit is alignment with EU trade regulations and processes. Brexit is the elephant in the room that is the inspiration to write this paper and the context that surrounds it. The aim of this paper is to contribute to the literature on identifying the salient factors (organisational processes, ability to learn and relearn, creative innovation, entrepreneurial action, resources and competences, stakeholder connectivity with firms, market entry before dominant technology is determined, market timing and ruggedness of the environment) that facilitate exploitable opportunities (tangible opportunities). It suggests that a hierarchical structure is required to examine the factors, and it is possible that the position of factors in the hierarchy may change due to environmental conditions. The paper further seeks to examine the role of intuition, gut feel or emotional intelligence in making an opportunity into a tangible opportunity.

\section{Theoretical framework: Timing opportunities}

The timing of an opportunity, e.g. to enter a market, will affect a firm's performance, and presents key questions in strategy research (Mitchell, 1991). Levels of management innovation (Foster, 1986), and organisation theory (Hannan \& Freeman, 1989) are influencers on the timing of opportunities. First mover advantage versus follower, i.e. order of entry (Lambkin, 1988) is linked to opportunity timing, but strategic capability also affects timing (Lee, 2009; Robinson, Fornell, \& Sullivan, 1992). Entering "new" markets such as China, India, and Brazil etc. is not influence by time, for in two years the opportunities will be just as tangible as now in 2017. Politicians conveniently avoid the issue of timing when it comes to Brexit. Making plans for the tangible opportunities of today, with no certainty that those opportunities will be available in the future, is a risk. Put another way, the "window of opportunity" may not be around in the future (Suarez, Grodal, \& Gotsopoulos, 2015:442). However, politicians consider opportunities and windows of opportunity with a degree of certainty based on rational behavior. Countries that we may want to trade with are strategies, not opportunities per se (Siciliano, 2016). The timing of entry between different entrants at different 
parts of the cycle has not been established. According to some authors timing advantages apply to stages in the industry cycle (Agarwal \& Bayus, 2004; Markides \& Geroski, 2005). Time of entry has also been linked to a firm's capability (Lee, 2009). Timing is linked to credibility and legitimacy, which affect first mover advantage (Aldwich \& Fiol, 1994; Dobrev \& Gotsopoulos, 2005). Market timing is linked to technological uncertainty (Sorenson, 2000). Thus the optimal time to enter a market is still to be defined (Suarez \& Lanzolla, 2007). Politicians conveniently forget or may not know that opportunities are influenced by many factors, some of which are explained above. Thus opportunities have to be qualified based on the state and influencers of the market and are not open to all firms or countries.

Further developing the influence of industry cycle on market timing suggests that the initial phase is divergence and the final stage convergence (Suarez, Grodal, \& Gotsopoulos, 2015). Divergence is associated with many stakeholders such as competitors, customers and differences in product design and functionality. In the ensuing stage after the initial stage a few firms start to become favorites due to the influences of stakeholders (Grodal, 2007; Kennedy, 2008; Suarez, Grodal, \& Gotsopoulos, 2015). The number of market opportunity moves to an inverted U with time. This is associated with the dominant category, and does not depend upon the dominant technological design. Successful categories encourage information exchange due to the need of stakeholders to engage and communicate with other stakeholders, known as the sociocognitive construct (Suarez, Grodal, \& Gotsopoulos, 2015). Emerging categories should be able to link with newness and novelty, which make the product distinctive to stakeholders, and should also be recognisable to be easily comprehensible (Bingham \& Kahl, 2013). This creates an internal tension between the recognisable and newness and novelty, and requires a recombining of existing products in innovative ways, such as voicemail (Berger \& Heath, 2005). Success of emerging categories depends upon dominant stakeholder endorsement (Negro, Kocak, \& Hsu, 2011), and is further qualified by current cultural acceptance or trends (Bingham \& Kahl, 2013). However, the dominant technological design is established through experimentation (Saurez \& Utterback, 1995). In the case of a novelty category any recombination that is practically permissible is possible (Suarez, Grodal, \& Gotsopoulos, 2015). Emerging dominant categories can only occur when other categories are marginalised or the perception of them changes so that these competing perceptions of the industry are abandoned. Where the distance between emerging categories is great more interaction between stakeholders is required to reach a consensus. The time for dominant categories to appear in the early phases of an industry increases and includes a connected number of categories. The time required for the dominant category to emerge in the early phases of an industry increases with the distance between categories (Suarez, Grodal, \& Gotsopoulos, 2015).

Early entry into a market, known as first mover advantage, has several positives such as presumptive resource allocation (Carroll \& Hannan, 1989), economies of scale in R\&D and production (Dixit, 1985; Klepper, 2002), reputational advantage, which positively influences the customer's ability to switch (Carpenter \& Nakamoto, 1990), and networking (Lieberman \& Montgomery, 1998). The counter-argument to these advantages includes the environmental and business uncertainties in the early stage of an industry (Suarez, Grodal, \& Gotsopoulos, 2015). The uncertainty is across technological and consumer demand, before a dominant design is entrenched (Utterback, 1994; Sorenson, 2000). Early entrants also have to contend with uncertainty relating to the market itself, which is driven by the collective actions of 
stakeholders (Santos \& Eisenhardt, 2009; Rosa et al., 1999). Firms that enter after the emergence of a dominant category can focus on the "right" experimentation that is consistent with the dominant design and technology (Suarez, Grodal, \& Gotsopoulos, 2015). The window of opportunity that opens with the emergence of a dominant category remains available only for a limited time. The end of the window of opportunity is identified by the emergence of a dominant design, and the maturing industry forces concentration towards production considerations such as economies of scale (Suarez, Grodal, \& Gotsopoulos, 2015; Gort \& Klepper, 1982). This leads to a proposition that states "firms that enter during the time window between the emergence of the dominant category and emergence of a dominant design will tend to perform better than firms that enter during other phases" (Suarez, Grodal, \& Gotsopoulos, 2015:443). It would suggest that a reasonable assumption is the number of established categories is greater than the emergent categories within countries. First mover advantage is thus limited in scope when considering market entry into different countries. Market entry will be in dominant categories with defined technological design facilitated by the stakeholders. From a politician's perspective there are several opportunities, which are the sum of the emergent dominant categories and the established dominant categories. However, the window of opportunity is limited before industry maturity, which suggests that firms must enter countries and their markets sooner rather than later. This implies that the number of tangible opportunities (windows of opportunity available) is limited, and established dominant categories will tend to hold more intangible opportunities. According to Suarez, Grodal, and Gotsopoulos (2015), firms will seek to gain advantage in established categories to keep competitors out through deliberate actions and engagement with stakeholders. Firms need to create and seek emerging dominant categories to drive growth and to obtain market leadership positions.

The challenge for firms is to enter before the start of the emergent dominant category is in place, which will require research on windows of opportunity in new markets. To define the end-point of the window of opportunity many suggestions have surfaced from emergence of a dominant design (technological influence), which causes a shift in competition, to economies of scale and production process (Klepper, 1997; Utterback, 1994). Defining the start of an emerging category is far more challenging. One suggestion by Christensen, Suarez, and Utterrback (1999) is that the window of opportunity for entering an industry happens "during the period just prior to the emergence of a dominant product design" (p. 213). Markides and Geroski (2005) suggest that "fast-second" firms enter an industry "just when the dominant design is about to emerge" (p. 120). Specific guidelines based on quantitative analysis were suggested by Agarawal and Bayus, (2004) and Lee (2009) by counting the number of firms entering the industry before take-off, firms that enter between propelling sales and take-off in the number of firms, and finally firms entering after the propelling increase in sales. Statistical techniques using discriminant analysis give results that vary between industries (Agarwal \& Gort, 2001). A firm proactively inviting stakeholders to engage in a new category by drawing them away from an established category is taking a risky strategy, because the firm is attempting to draw stakeholders towards their perception of the industry (Lounsbury \& Glynn, 2001). The firm must execute a strategy that demonstrates consistency of product positioning, and also by moulding stakeholders' perceptions (Santos \& Eisenhardt, 2009).

\section{Environment and uncertainty}


Managers are required to interpret varying environmental signals and link the analysis to the strategic impact on their firm, including how it affects the firm's performance (Dutton, Fahey, \& Narayanan, 1983). One expectation is that managers can condense complex environmental situations into meaningful simple interpretations such as whether the environment harbours any threats or opportunities (Jackson \& Dutton, 1987; Julian \& Ofori-Dankwa, 2008). Strategic issues require interpretation of organisational action and decision-making (Gilbert, 2006; Julian \& Ofori-Dankwa, 2008). Opportunities are associated with strategic issues and thus tangible opportunities are a function of the resources and competences of the firm. One cannot then talk about blanket opportunities as politicians tend to when stating that the whole world has opportunities. One firm's meat could be another firm's poison. Reasoning using analogies is based on past experience that could be applied to similar situations, enabling inferences to be drawn about a present situation (Holyoak, 2005). Strategists apply analogical reasoning in novel environments (Gavetti \& Rivikin, 2005; 2007). Researchers go further to contend that analogical reasoning helps organisational adaption in complex environments (Gavetti, Levinthal, \& Rivikin, 2005). Environment scanning provides the data, but managers need to provide the meaning to facilitate learning and organisational action. The current environment and staff of the organisation and its collective past experiences are part of the process in understanding the current environment (Daft \& Weck, 1984). Consequently, strategic issues apply inferential reasoning to generate fallible hypotheses instead of drawing conclusions (Dutton, Fahey, \& Narayanan, 1983). Hypotheses inferred from the analysis guide managers through the decision-making process to realise perceived opportunities in the environment (Eisenhardt \& Sull, 2001). Opportunities need qualifying, and as suggested, Eisenhardt and Sull (2001) are referring to tangible opportunities. Environmental scanning more precisely needs to clearly identify tangible and intangible opportunities, which implies a hierarchical approach to seeking and exploiting opportunities.

The literature has established a link between strategic issues and the following organisational characteristics, such as strategy and information processing structure and culture (Thomas \& McDaniel, 1990), diversity of the top management team (Plambeck \& Weber, 2009), resource dependencies (Milliken, 1990), and experience, inertia and available resources (Denison et al., 1996). Further organisational links include the importance of information gathering and processing (Anderson \& Nichols, 2007) and past experience (Denison et al., 1996; Plambeck \& Weber, 2010). Wholey and Brittain (1989) suggest that environmental variation has dimensions classified as frequency (time between environmental changes), amplitude (the distance between successive changing environmental states), and predictability (the degree to which future states can be anticipated).

Jackson and Dutton (1988) suggest environments are classified as favorable or unfavorable, which are broad indicators and need refining to improve their accuracy. Miller and Lin (2014) advance environmental indicators beyond those suggested by Jackson and Dutton (1988). Miller and Lin (2014) draw several conclusions from their research on interpreting environments by reasoning analogically:

1. The level of interpretation accuracy improves over time for best available match and exact match. However, old memories often interfere in the interpretation process, and often mislead organisations that are self-satisficing in what is acceptable to the organisation. Satisficing organisations in dynamic 
environments should be abandoned in favor of the best match from analogical reasoning.

2. Dynamic environments reduce a firm's performance in the short term, but enhance experiential learning, thus improving the accuracy of analogical reasoning to the best available match over the long term. This conclusion is consistent with research by Gary, Wood, and Pillinger (2012). Miller and Lin (2014) also found that new entrants that enter dynamic environments invest heavily in learning, but receive weak results in the short run. Constantly challenging the environments via participation gives rise to unique knowledge, which enables them to cope with environmental dynamism.

3. Best matches generally outperform exact match reasoning when the dimensions of unpredictability and ruggedness (the extent to which interactions among environmental elements affect the resulting state) are high. When experience is limited, decision-making needs to use what is known, and not wait to acquire the ideal know-how. This is a probable situation in the case of a hard Brexit, because to make effective decisions about tangible opportunities will require acting on what the organization knows when entering new markets and industries. The Brexiteers (who voted to leave the EU) are correct that in the long term market entries will become tangible opportunities. How long will it take to develop the level of analogical reasoning?

4. In environments that have a high degree of ruggedness, satisficing can deliver results that are worse than random guessing. Thus satisficing is sensible in the early stages of environments with low unpredictability or low frequency of change. Only in stable or predictable environments should satisficing be accommodated, otherwise satisficing should be abandoned in favor of inferential reasoning.

5. Satisficing is an approach to reduce performance volatility when environmental change occurs infrequently, but the penalty is that lower risk comes with a cost to performance. Organisations that are extremely risk averse would accept the trade-off of risk-return involving satisficing over the long run.

\section{Competitive advantage and sustainable opportunities}

The resource-based view is a significant theoretical framework in understanding competitive advantage (Barney, 1991; Wernerfelt, 1984; Peteraf, 1993; Peteraf \& Barney, 2003). The sustainability of competitive advantage is in linked resources that are valuable, rare, inimitable and non-substitutable (VRIN) for a given industry or market (Barney, 1991; Peteraf, 1993). Competitors with similar resources may not be able to apply VRIN successfully to gain a competitive advantage. The window of opportunity becomes activated at the emergence of the dominant category, and it is suggested that at this stage a competitive advantage could be created and extended. Firms need to develop resources at the early dominant category or at the window of opportunity based on the VRIN framework. Competitive advantage does not last forever but is affected by environmental dynamics and complexity, which by implication will influence the application of VRIN.

The leveraging of core resources based on the RBV approach is another approach to gaining a competitive advantage (Hamel \& Prahalad, 1990; Collis \& Montgomery, 1995). Ownership of the core resources is how the competitive advantage is derived, these specific resources being rare, non-substitutable and valued in one or several markets (Bingham \& Eisenhardt, 2007). Value creation can also be derived from 
complementary resources linked to the core resources. It may not be sufficient to own core resources to leverage a competitive advantage across markets or industries (Bingham \& Eisenhardt, 2007). Gilbert (2006) found in a study that complementary resources were necessary in the newspaper industry in the online as well as traditional newspaper markets. The recombination effect of core resources and complementary resources is a way forward for the Brexit environment, and the mixture only requires moderate linkage between them (Bingham \& Eisenhardt, 2007). This assumes that changes in the Brexit environment can be compensated by a firm's knowledge-based leverage of the expertise to gain a competitive advantage. If the firm is dependent on physical resources, the leveraging approach to competitive advantage will be shortterm (Bingham \& Eisenhardt, 2007; Danneels, 2002).

Opportunity logic comes from a firm's ability to capture attractive and fast-moving opportunities based on its resources to create superior value (Eisenhardt \& Martin, 2000). To unlock the Brexit opportunities will require an entrepreneurial approach by firms, coupled with innovative ideas. Seizing these opportunities requires the application of one or more organisational processes, from the ability to master mergers and acquisitions, alliances and internationalisation and product innovation (Eisenhardt \& Sull, 2001). Attractive opportunities are those with the highest profit and revenues, because these are a measure of superior performance (Davis, Eisenhardt, \& Bingham, 2007). In the context of this paper, attractive opportunities are tangible opportunities, but intangible opportunities can be converted into tangible opportunities with the "right" resources. Intangible opportunities will require reworking of organisational processes to convert them into tangible or attractive opportunities. Firms in the Brexit environment will have to redesign organisational processes, and these will need to evolve to meet the changing environment of Brexit. The uncertainty that Brexit is creating is making designing organisational processes and identifying tangible opportunities more challenging. Because opportunity logic requires flexibility in organisational processes they are semi-structured compared to leverage opportunity logic, which requires less flexibility in the organisational processes (Bingham \& Eisenhardt, 2007; Nelson \& Winters, 1982). Opportunity logic requires management to identify opportunities spontaneously in unpredictable and non-linear environments (Davis, Eisenhardt, \& Bingham, 2007). To exploit tangible opportunities in a Brexit-type environment executives should deploy an opportunity logic strategy, especially in a hard Brexit environment. However, in a soft Brexit environment a leveraging opportunity strategy would be a more effective strategy. However, this should not stop the search for spontaneous opportunities in a soft Brexit environment.

\section{Implications for Management}

The above discussion on competitive advantage has implications for Brexit. A hard Brexit effectively changes the environmental landscape by adding to the complexity and dynamics in the EU markets and industries for UK firms and also overseas firms operating from the UK. A degree of relearning of a firm's strategy will be required, which will impact how tangible opportunities can be exploited. Firms will be effectively trying to recalculate their competitive advantage and realign it with the new environmental reality. This is equivalent to trying to re-enter dominant categories that are already established. An appropriate strategy is to use the Blue Ocean strategy canvas or scan the environment for white spaces to innovate to create new emergent categories. This will require UK firms to become innovator-engines and become more 
responsive to tangible and intangible opportunities, creating more first-mover tangible opportunities.

Does this mean that a soft Brexit spikes the innovator-engines less? In one sense this could be true, because there is a need to work harder with a hard Brexit than a soft Brexit situation. However, the hard work required by a hard Brexit is related to retaining a firm's competitive position and not to improvement. Soft Brexit tangible opportunities are linked to future growth on top of existing growth, and strengthening VRIN factors to develop new or additional sustainability relative to existing competitors. Improvement in competitive advantage and sustainability of competitive advantage is relatively short-term in a soft Brexit environment, but a hard Brexit requires the competitive advantage calculus to be recalculated and this could be over the medium to long term.

Parnell and Dent (2009) suggest that at the beginning stages of a new emergent category initial success is required to achieve long-term success. Hard Brexit is the equivalent for UK operators of entering a market or industry at the beginning, because of the new environment and they are at the initial stages of this new environment. Environmental changes in a hard Brexit require more chances to be taken with tangible opportunities, and for them to be successful a greater degree of adaptability and flexibility is required. Tangible opportunities are based on a hierarchy as the literature suggests that emergent categories are more fruitful than entering established or mature markets (Suarez, Grodal, \& Gotsopoulos, 2015). The levels of certainty, complexity and stability influence the approaches employed to develop the "best" strategy to exploit tangible opportunities. An opportunity (tangible opportunity) logic to creating value and building a competitive advantage will require an entrepreneurial and innovative approach by firms.

Executives have two strategies available to cope with a Brexit environment. Leverage opportunity strategies are the dominant strategies for a soft Brexit to exploit tangible opportunities, but this is not to preclude logic opportunity strategies. In a hard Brexit environment a logic opportunity strategy would be the dominant strategy. Logic strategy will give firms the opportunity to redesign their organisational processes. All strategies require a degree of flexibility, but operating a dominant strategy that is logic opportunity-centric will require a greater degree of flexibility and adaptability than leverage opportunity strategies.

\section{Future Research}

The impact of Brexit, be it soft or hard, is likely to make UK firms innovative-engines and become greater risk-takers in innovative terms. Will Brexit move the UK towards a long-term approach to investment and innovation? An associated area is the cultural effects of Brexit on strategy development and strategy implementation. Opportunities that are not currently exploitable by a firm, known as intangible opportunities, will require strategies to bring them back into play for the firms. What strategies are appropriate to achieve this outcome?

\section{Conclusion}

Opportunities require classifying into tangible or intangible; to speak of opportunities in a business sense without broadly classifying them into categories is to mislead. 
There are windows of opportunity in emergent categories and the best stage to be successful in that market or industry. Hard Brexit will contain intangible opportunities and soft Brexit will include tangible opportunities, but they are not mutually exclusive. Some firms will have core resources and competences to succeed in a hard Brexit environment, but these are likely to be limited. Windows of opportunity are rather like once-in-a-lifetime opportunities. Entering an established or mature industry is challenging, because the stakeholders have decided the shape of the industry. Hard Brexit will require more prising open of established markets than a soft Brexit. Strategies will be required to minimise the effects of Brexit, but a possible approach is to recombine core resources and complementary competences to derive and develop new positions of competitive advantage.

\section{Bibliography}

Agarwal, R., \& Bayus, B. L. (2004). Creating and surviving in new industries. Advances in Strategic Management, 21, 107-130.

Agarwal, R., \& Gort, M. (2001). First-mover advantages and the speed of competitive entry. Journal of Law and Economics, 64, 161-177.

Ahmed, K. (2016). What does 'hard' or 'soft' Brexit mean? Retrieved May 7, 2018, from http://www.bbc.co.uk/news/business-37500140.

Aldrich, H. E., \& Fiol, M. (1994). Fools rush in? The institutional context of industry construction. Academy of Management Review, 19, 645-670.

Anderson, M. H., \& Nichols, M. L. (2007). Information gathering and changes in threat and opportunity perceptions. Journal of Management Studies, 44, 367-387.

Barney, J. B. (1991). Firm resources and sustained competitive advantage. Journal of Management, 17(1), 99-120.

Berger, J. A., \& Heath, C. (2005). Idea habitats: How the prevalence of environmental cues influences the success of ideas. Cognitive Science, 29, 195-221.

Bingham, C. B., \& Eisenhardt, K. M. (2007). Position, leverage and opportunity: A typology of strategic logics linking resources and competitive advantage. Managerial and Decision Economics, 29, 241-256.

Bingham, C. B., \& Kahl, S. (2013). The process of schema emergence: Assimilation, deconstruction, unitization and plurality of analogies. Academy of Management Journal, 56 (1), 14-34.

Carpenter, G. S., \& Nakamoto, K. (1990). Competitive strategies for late entry into a market with a dominant brand. Management Science, 36, 1268-1278.

Carroll, G. R., \& Hannan, M. T. (1989). Density delay in the evolution of populations of newspaper organizations: A model and five empirical tests. Administrative Science Quarterly, 34, 411-430.

Christensen, C. M., Suarez, F. F., \& Utterback, J. M. (1999). Strategies for survival in fast-changing industries. Management Science, 44, 207-220. 
Collis, D. J., \& Montgomery, C. A. (1995). Competing on resources. Harvard Business Review, 73(4), 118-128.

Daft, R. L., \& Weick, K. E. (1984). Toward a model of organizations as interpretation systems. Academy of Management Review, 9, 284-295.

Danneels, E. (2002). The dynamics of product innovation and firm competencies. Strategic Management Journal, 23, 1095-1121.

Davis, J. P., Eisenhardt, K. M., \& Bingham, C. B. (2007). Complexity theory, market dynamism, and the strategy of simple rules. Stanford Technology Ventures Program Working Paper.

Denison, D. R., Dutton, J. E., Kahn, J. A., \& Hart, S. L. (1996). Organizational context and the interpretation of strategic issues: A note on CEOs' interpretations of foreign investment. Journal of Management Studies, 33, 453-474.

Dixit, A. (1985). The role of investment in entry deterrence. Economic Journal, 9o, 95-106.

Dobrev, S. D., \& Gotsopoulos, A. (2010). Legitimacy vacuum, structural imprinting, and the first-mover disadvantage. Academy of Management Journal, 53, 1153-1174.

Dutton, J. E., Fahey, L., \& Narayanan, V. K. (1983). Toward understanding strategic issue diagnosis. Strategic Management Journal, 4, 307-323.

Eisenhardt, K. M., Martin, J. (2000). Dynamic Capabilities: What are they?. Strategic Management Journal, 21, 1105-1121.

Eisenhardt, K. M., \& Sull, D. N. (2001). Strategy as simple rules. Harvard Business Review, 79(1), 107-116.

Foster, R. (1986). Innovation: The attacker's advantage. Melbourne, Australia: Summit Books.

Hannan, M. T., \& Freeman, J. (1989). Organizational ecology. Cambridge, MA: Harvard University Press.

Gary, M. S., Wood, R. E., \& Pillinger, T. (2012). Enhancing mental models, analogical transfer, and performance in strategic decision making. Strategic Management Journal, 33, 1229-1246.

Gavetti, G., Levinthal, D., \& Rivkin, J. W. (2005). Strategy making in novel and complex worlds: The power of analogy. Strategic Management Journal, 26, 691-712.

Gavetti, G., \& Rivkin, J. W. (2007). On the origin of strategy: Action and cognition over time. Organization Science, 18, 420-439.

Gavetti, G., \& Rivkin, J. W. (2005). How strategists really think: Tapping the power of analogy. Harvard Business Review, 83(4), 54-63.

Gilbert, C. G. (2006). Change in the presence of residual fit: Can competing frames coexist? Organization Science, 17, 150-167. 
Gort, M., \& Klepper, S. (1982). Time paths in the diffusion of product innovations. Economic Journal, 92, 630-653.

Grodal, S. (2007). The Emergence of a New Organizational Field - Labels, Meaning and Emotions in Nanotechnology. Palo Alto, California: Stanford University.

Holyoak, K. J. (2005). Analogy. In The Cambridge handbook of thinking and reasoning, Holyoak, K. J., \& Morrison, R. G. (Eds.). New York: Cambridge University Press, pp. 117-142.

Jackson, S. E., \& Dutton, J. E. (1988). Discerning threats and Opportunities. Administrative Science Quarterly, 33, 370-387.

Julian, S. D., \& Ofori-Dankwa, J. C. (2008). Toward an integrative cartography of two strategic issue diagnosis frameworks. Strategic Management Journal, 29, 93-11.

Kennedy, M. T., Lo, J. Y. C., \& Lounsbury, M. (2010). Category currency: The changing value of conformity as a function of ongoing meaning construction. Research in the Sociology of Organizations, Categories in Markets: Origins and Evolution, 31, 369-397.

Klepper, S. (2002). Firm survival and the evolution of oligopoly. RAND Journal of Economics, 33, 37-61.

Klepper, S. (1997). Entry, exit, growth and innovation over the product life cycle. American Economic Review, 86, 562-583.

Kim, W. C., \& Mauborgne, R. (2005). Blue ocean strategy: From theory to practice. California Management Review, 47(3), 105-121.

Lambkin, M. (1988). Order of entry and performance in new markets. Strategic Management Journal, 9, 127-140.

Lee, G. (2009). Understanding the timing of 'fast-second' entry and the relevance of capabilities in invention vs. commercialization. Research Policy, 38, 86-95.

Lieberman, M. B., \& Montgomery, D. B. (1998). First-mover (dis)advantages:

Retrospective link with resourcebased view. Strategic Management Journal,19, 11111125 .

Lounsbury, M., \& Glynn, M. A. (2001). Cultural entrepreneurship, stories, legitimacy, the acquisition of resources. Strategic Management Journal, 22, 545-564.

Markides, C., \& Gerosk, P. A. (2005). Fast second: How smart companies bypass radical innovation to enter and dominate new markets. San Francisco, CA: JosseyBass.

Miller, K. D., \& Lin, Shu-Jou (2015). Analogical reasoning for diagnosing strategic issues in dynamic and complex environments" Strategic Management Journal, 36, 2000-2020. 
Milliken, F. J. (1990). Perceiving and interpreting environmental change: An examination of college administrators' interpretation of changing demographics. Academy of Management Journal, 33, 42-63.

Mitchell, W. (1991). Dual clocks: Entry order influences on incumbent newcomer market share and survival when specialized assets retain their value. Strategic Management Journal, 12, 85-100.

Negro, G., Koak, Z., \& Hsu, G. (2011). Research on categories in the sociology of organizations. Research in the Sociology of Organizations, 31, 3-35.

Nelson, R. R., \& Winter, S. G. (1982). An evolutionary theory of economic change. Cambridge, MA: Harvard University Press.

Parnell, J. A., \& Dent, E. B. (2009). The role of luck in the strategy-performance relationship. Management Decision, 47(6), 1000-1021.

Peteraf, M. A., \& Barney, J. B. (2003). Unraveling the resourcebased tangle. Managerial and Decision Economics, 24, 309-323.

Peteraf, M. A. (1993). The cornerstones of competitive advantage: A resource based view. Strategic Management Journal, 14(3), 479-488.

Plambeck, N. \& Weber, K. (2010). When the glass is half full and half empty: CEOs' ambivalent interpretations of strategic issues. Strategic Management Journal, 31, 689-710.

Plambeck, N., \& Weber, K. (2009). CEO ambivalence and responses to strategic issues. Organization Science, 20, 993-1010.

Porter, M. E. (1996). What is Strategy? Harvard Business Review, 74(6) NovemberDecember, 61-78.

Pralahad, C. K., \& Hamel, G. (1990). The core competence of the corporation. Harvard Business Review, May-June, 79-90.

Robinson, W. T., Fornell, C., \& Sullivan, M. (1992). Are market pioneers intrinsically stronger than later entrants? Strategic Management Journal, 13, 609-624.

Rosa, J. A., Porac, J. R., Runser-Spanjol, J., \& Saxon, M. S. (1999). Sociocognitive dynamics in a product market. Journal of Marketing, 63, 64-77.

Santos, F. M., \& Eisenhardt, K. M. (2009). Constructing markets, shaping boundaries: Entrepreneurial power in nascent fields. Academy of Management Journal, 52, 643-671.

Siciliano, J. (2016). SWUF analysis: A new way to avoid the 'opportunity' error of SWOT. Journal of the Academy of Business Education, Winter, 201-208.

Sorenson, O. (2000). Letting the market work for you: An evolutionary perspective on product strategy. Strategic Management Journal, 21, 577-592. 
Suarez, F. F., Grodal, S., \& Gotsopoulos, A. (2015). Perfect timing? Dominant category, dominant design, and opportunity for firm entry. Strategic Management Journal, 36, 437-448.

Suarez, F. F., \& Lanzolla, G. (2007). The role of environmental dynamics in building a first mover advantage theory. Academy of Management Review, 32, 377-392.

Suarez, F. F., \& Utterback, J. M. (1995). Dominant design and the survival of firms. Strategic Management Journal, 16, 415-430.

Thomas, J. A., \& McDaniel, R. R., Jr. (1990). Interpreting strategic issues: Effects of strategy and the information processing structure of top management teams. Academy of Management Journal, 33, 286-306.

Utterback, J. M. (1994). Mastering the dynamics of innovation. Boston, MA: Harvard Business School Press.

Wernerfelt, B. (1984). A resource-based view of the firm. Strategic Management Journal, 5, 171-180.

Wholey, D. R., \& Brittain, J. (1989). Characterizing environmental variation. Academy of Management Journal, 32, 867 - 882. 